tients with coronary artery disease treated with beta-blocking drugs. Am J Cardiol 1985;55:33-6.

34. Mitler MM, Kripke DF. Circadian variation in myocardial infarction [Letter]. N Engl J Med 1986;314:1187-8.

35. Figueras J, Singh BN, Ganz W, Chamzi Y, Swan HJC. Mechanism of rest and nocturnal angina: observations during continuous hemodynamic and electrocardiographic monitoring. Circulation 1979;5:955-68.

36. Sibley DR, Lefkowitz RJ. Molecular mechanisms of receptor desensitization using the beta-adrenergic receptor-coupled adenylate cyclase system as a model. Nature 1985;317:124-9.

37. Fox KM, Deanfield JE, Selwyn AP, Krikler S, Wright CA Treatment of chronic stable angina pectoris with nifedipine. In: Kaltenbach M, Neufeld HN, eds. Fifth International Nifedipine Symposium. Amsterdam: Excerpta Medica, 1982:197204.

38. Yokoyama M, Kolzumi T, Fujitani K, Mizutami T, Fukuzaki $\mathrm{H}$. Adverse response to nifedipine in unstable angina pectoris. Chest 1982;81:646-8.

39. Tenis S, Bourdillon PD, Cheng DT, Pitt B. Direct cardiac and peripheral vascular effects of intracoronary and intravenous nifedipine. Am J Cardiol 1986;58:25-30.

40. Egstrup K. Asymptomatic myocardial ischemia as a predictor of cardiac events after coronary artery bypass grafting for stable angina pectoris. Am J Cardiol 1988;61:248-52.

41. Rocco M, Nabel E, Campbell S, Goldman L, Barry J, Mead K, Selwyn A. Prognostic importance of myocardial ischemia detected by ambulatory monitoring in patients with stable coronary artery disease. Circulation 1988;78:877-84.

42. Tzivoni D, Weisz G, Gavish A, Zin D, Kern A, Stern S. Comparison of mortality and myocardial infarction rates in stable angina pectoris with or without ischemic episodes during daily activities. Am J Cardiol 1989;63:273-6.

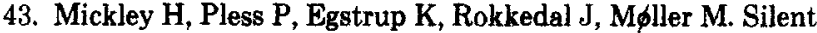
ischemia is a predictor of severe angina pectoris after first myocardial infarction [Abstract]. Eur Heart J 1988:9:314.

44. Gottlieb SO, Weisfeldt ML, Ouyang P, Mellits ED, Gerstenblith $G$. Silent ischemia as a marker for early unfavourable outcomes in patients with unstable angina. N Engl J Med $1986 ; 314: 1214-9$.

\title{
Transmural distribution of myocardial edema by NMR relaxometry following myocardial ischemia and reperfusion
}

\begin{abstract}
To determine the distribution and extent of myocardial edema resulting from lschemia and reperfusion, seven open-chest dogs underwent occlusion of the left circumflex coronary artery for 2 hours (group I), and 10 underwent occlusion for 2 hours and reperfusion for 2 hours (group II). Proton nuclear magnetic resonance 8pectroscopy (T1 and T2 relaxation times) and percent water content were determined to quantitate the amount of edema. There was a transmural increase of the $\mathrm{T} 1$ relaxation time of the central ischemic zone in groups $I$ and II, although this increase was significantly greater in group II in both the subendocardium (group $I=707.8 \pm 12.5$ msec, group ||$=813.2 \pm 36.2$ meec; $p<0.01$ ) and subeplcardium (group $I=641.7 \pm 20.5$ msec, group $\|=760.5 \pm 34.7$ msec; $p<0.01$ ). These increases were also observed in the $\mathrm{T} 2$ weighted relaxation time in the subendocardium (group $\mathrm{I}=54.7 \pm 0.8 \mathrm{msec}$, group $\|=78.7 \pm 6.3$ msec; $p<0.005$ ) and subepicardlum (group $I=54.0 \pm 1.4$ msec, group $\|=73.1 \pm 4.0$ msec; $p<0.001$ ). Transmural differences were evident between the myocardlal layers with increased T1 relaxation times $(p<0.01)$ in the subendocerdium in both groups. Similar increases were noted in the percent water content of the myocardlum. Thus $\mathrm{T}_{1}$ and $\mathrm{T} 2$ relaxation times lengthened with an increase in myocardial water content following occlusion, and these relaxation times were augmented by reperfusion. We conclude that lschomia-induced odema occurs in a transmural distribution from subendocardium to subopicardtum following occlusion, and this edema ls further enhanced by reperfusion. (AM HEART J 1991;122:655.)
\end{abstract}

Beth L. Karolle, BS, Robert E. Carlson, BS, Alex M. Aisen, MD, and Andrew J. Buda, MD. Ann Arbor, Mich.

From the Cardiology Division, Department of Internal Medicine and Department of Radiology, University of Michigan Medical Center.

This work was supported in part by a Grant-in-Aid from the American Heart Association, Inc., Dallas, Texas, and by R01 HL 34691 from the National Heart, Lung, and Blood Institute, National Institutes of Health, Bethesda, Maryland. Ms. Karolle was a recipient of a Student Research Fellowship from the American Heart Association of Michigan.
Received for publication Jan. 17, 1991; accepted March 4, 1991.

Reprint requests: Andrew J. Buda, MD, Chief, Cardiology Section, Tulane University School of Medicine, 1430 Tulane Ave., New Oleans, LA 70112.

$4 / 1 / 30322$ 
Cardiac nuclear magnetic resonance (NMR) imaging is potentially able to detect and quantify zones of hypoperfused and infarcted myocardium. $.^{1-13} \mathrm{Be}-$ cause the NMR signal is determined largely by the proton density contained in the edema of the zone of acute myocardial ischemia, there is a renewed interest in characterizing myocardial edema following coronary occlusion and reperfusion. NMR techniques quantify this myocardial edema by expressing prolonged relaxation times and increased signal intensities on NMR images. However, areas of prolonged relaxation times and increased signal intensity correspond better to the hypoperfused zones at risk than to the zones of actual infarction, thus overestimating infarct size. ${ }^{3,11}$ This suggests that edema extends beyond the necrotic zone into viable at-risk myocardium. Therefore a thorough understanding of the distribution of edema formation is necessary for appropriate interpretation of NMR cardiac images. Moreover, characterization of edema may provide additional insights into the pathophysiology of ischemia and reperfusion.

Accordingly, we designed a study to examine the transmural distribution of myocardial edema in the setting of myocardial ischemia and coronary reperfusion. Our hypotheses were: (1) a transmural gradient of myocardial edema will occur during myocardial ischemia and (2) the transmural extent of edema in the ischemic and reperfused myocardium will be greater than in the ischemic myocardium without reperfusion.

\section{METHODS}

Experimental procedures complied with the guidelines of the University of Michigan Committee on the Use and Care of Animals. The University of Michigan is accredited by the American Association of Accreditation of Laboratory Animal Care, and animal care and use conforms to the standards in "The Guide for the Care and Use of Laboratory Animals," Department of Health, Education, and Welfare, publication number NIH78-23, revised 1978. Seventeen male mongrel dogs (approximately $25 \mathrm{~kg}$ ) were anesthetized intravenously with $10 \mathrm{ml}$ of thiamylal sodium $(5 \%)$ followed by $2 \mathrm{ml}$ of pentobarbital sodium $(30 \mathrm{mg} / \mathrm{kg})$ and were ventilated by a Harvard respirator (Harvard Apparatus Inc., S. Natick, Mass.) via an endotracheal tube. Polyvinyl catheters were inserted into the left internal jugular vein for adminstration of fluids and into left carotid and femoral arteries for microsphere reference withdrawal. Measurement of mean arterial pressure was obtained via a catheter in the right femoral artery. A left thoracotomy was performed in the fifth intercostal space, the lungs were retracted, and the heart was suspended in a pericardial cradle. The left atrial appendage was catheterized for injection of radiolabeled microspheres and for measurement of left atrial pressure. The left circumflex coronary artery was dissected away from the heart proximally, and a snare occluder was placed around it (Fig. 1).

Experimental protocol (Fig. 2). The dogs were randomly assigned to two groups: 2 hours of occlusion (group I, $n=7$ ), and 2 hours of occlusion followed by 2 hours of reperfusion (group II, $n=10$ ). The electrocardiogram (ECG) was monitored from limb leads. Hemodynamic measurements (mean arterial pressure, left atrial pressure, and heart rate) and two-dimensional echocardiography were performed at baseline, at 2 hours of occlusion, and at 1 and 2 hours of reperfusion. Radioactive-labeled microspheres $\left({ }^{113} \mathrm{Sn},{ }^{141} \mathrm{Ce},{ }^{103} \mathrm{Ru},{ }^{51} \mathrm{Cr},{ }^{46} \mathrm{Sc}\right.$ ) for myocardial blood flow determination were injected into the left atrium at baseline, at 2 hours of occlusion, and at 2 hours of reperfusion. Microsphere injection was performed simultaneously with reference withdrawal from the femoral and carotid arteries at a rate of $7 \mathrm{ml} / \mathrm{min}$ via a Harvard withdrawal pump; this withdrawal was initiated a few seconds prior to and continued until 2 minutes following injection. Lidocaine was given intravenously $(50 \mathrm{mg}) 2$ minutes before both occlusion and reperfusion. At the time of sacrifice, $10 \mathrm{ml}$ of sodium heparin was injected, and a lethal intravenous injection of pentobarbital sodium and saturated potassium chloride was given.

Edema determination. Following sacrifice, the hearts were excised, sliced into $5 \mathrm{~mm}$ transverse sections, and weighed. Immediately afterward, $1 \mathrm{gm}$ subendocardial and subepicardial sections were taken from both the central ischemic zone and the central normal zone and were sealed in a dry test tube for NMR spectroscopy. The positioning of the sample, the radiofrequency pulses, and the detector phase were optimized for each sample prior to acquisition of relaxation times. Relaxation times were obtained from an IBM PC-20 Minispec relaxometer (IBM Corp., Atlanta, Ga.) operating at $20 \mathrm{MHz}$ at $40^{\circ} \mathrm{C}$. $\mathrm{T} 1$ values were calculated from a least squares fit of 20 inversion recovery points. T2 values were calculated from a least squares fit of 150 Carr, Purcell, Meiboon-Gill (CPMG) pulse sequence points to obtain a multiple exponent, although only the dominant component was analyzed. Once the relaxometer was calibrated for a sample, the relaxation times were acquired three times and were then averaged to determine the final values for $\mathrm{T} 1$ and $\mathrm{T} 2$ times of each tissue section. Percent water content was determined from these same myocardial samples that were subsequently dried and reweighed to determine the amount of water present $\left(\% \mathrm{H}_{2} \mathrm{O}=\right.$ wet wt - dry wt/wet wt $)$.

Regional blood flow analysis. Two midpapillary slices of the hearts were cut into approximately 16 sectors. From these sections, the two most ischemic sectors were chosen for the ischemic zone, and two sections 180 degrees from the ischemic zone were chosen for the normal zone. These sectors were further sectioned into three layers defined as subendocardium, midmyocardium, and subepicardium. The samples were weighed and placed into counting vials, and radioactivity was determined by a gamma scintillation counter from oven-dried arterial withdrawal samples and from air-dried myocardial samples. The counts were corrected for background and overlap. Myocardial blood flow 


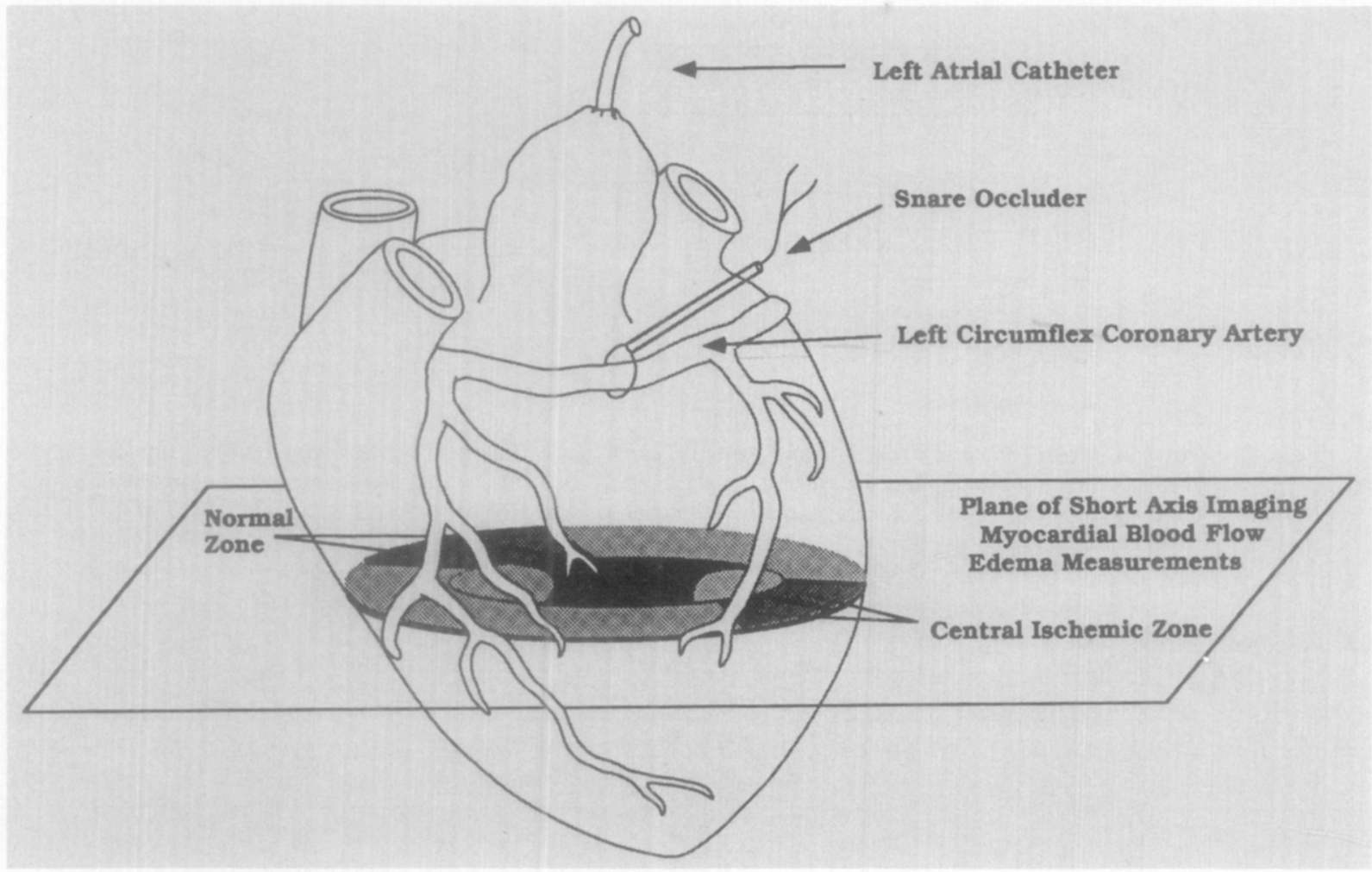

Fig. 1. Schematic representation of the instrumentation of the heart and plane of short-axis imaging. The left circumflex coronary artery was dissected from the heart, and a snare occluder was placed around it. The left atrial appendage was catheterized for measurement of left atrial pressure and injection of radiolabeled microspheres for determination of regional blood flow. The short-axis imaging plane for two-dimensional echocardiography is shown at the midpapillary muscle level. This was also the level for determination of myocardial blood flow and edema measurements. The region of the central ischemic and normal zones from which the samples were taken are illustrated.

was calculated as $\mathrm{Qm}=\mathrm{Cm} \times \mathrm{Qr} / \mathrm{Cr}$, where $\mathrm{Qm}=\mathrm{myo}$ cardial blood flow (in milliliters per minute), $\mathrm{Cm}=$ counts per minute in the tissue sample, $\mathrm{Qr}=$ the reference withdrawal rate (in milliliters per minute), and $\mathrm{Cr}_{r}=$ counts per minute in the reference arterial sample. Flow per gram of tissue was then determined by dividing sample flows by sample weight. The myocardium was considered severely ischemic when subendocardial myocardial blood flow was less than $0.2 \mathrm{ml} / \mathrm{min} / \mathrm{gm}$.

The same coordinate system was used for all measurements that divided the slice into 16 radial sectors (of 22.5 degrees each) at the midpapillary muscle level. This coordinate system provided a means to localize the central normal and central ischemic zones as determined by histochemical staining, wall thickening, and edema measurements. The central ischemic zone was defined in the middle of the posterior papillary muscle at 135 degrees. The normal zone was defined at 180 degrees from the center of the ischemic zone at 315 degrees.

Functional analysis. Short-axis two-dimensional echocardiography was performed at the level of the midpapillary muscle; the data were subsequently analyzed on a microcomputer-based video digitizing system. End-diastolic and end-systolic frames were selected by using the onset of the $Q$ wave in lead II to define end diastole and the smallest ventricular cavity to define end systole. Endocardial and epicardial borders were traced directly on the video display for three successive beats during normal sinus rhythm using a digitizing tablet. Analysis was performed using a radial contraction model with a fixed diastolic center of mass at 22.5 degree intervals over the full left ventricular circumference. The mid-point of the posterior papillary muscle was fixed at 135 degrees for correction of rotation. Wall thickening was calculated as: [(end-systolic wall thickness - end-diastolic wall thickness)/end-diastolic wall thickness] $\times 100 \%$.

The normal range of wall thickening was determined from a functional map of the beseline images for three cardiac cycles and $95 \%$ tolerance limits were determined for each animal. These limits were used for comparison with occlusion and reperfusion functional maps and abnormalities were expressed as the circumferential extent and degree of dysfunction. ${ }^{14}$ The extent of dysfunction was defined as the number of degrees where the occlusion or reperfusion functional map intercepted the lower control tolerance limit. The degree of dysfunction was defined as the area of the map, determined by planimetry, contained within the dysfunctional area. 


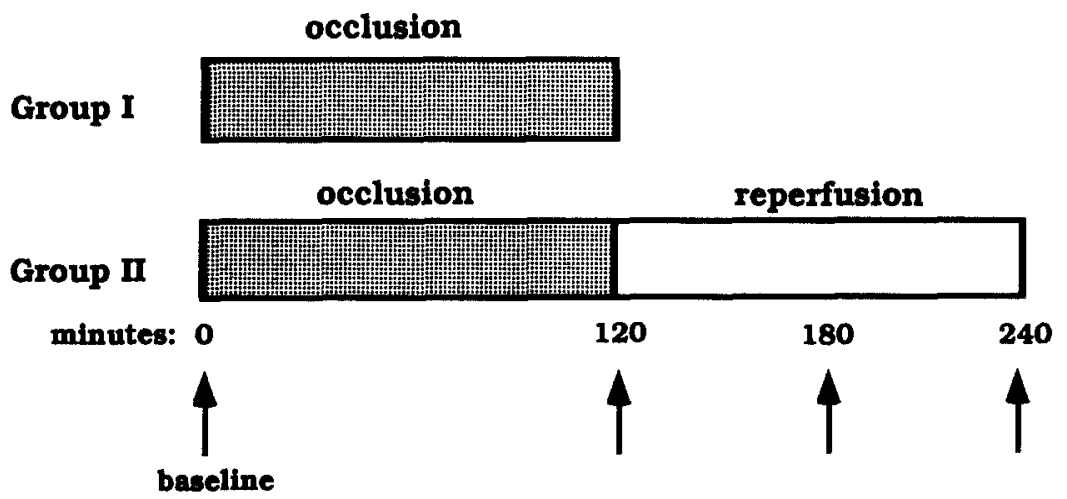

Fig. 2. Protocol. Group I (seven dogs) underwent 2 hours of occlusion without reperfusion; group II (10 dogs) underwent 2 hours of occlusion plus 2 hours of reperfusion. Time point measurements are represented by arrows and were obtained at baseline, at 2 hour of occlusion, and at 2 hours of reperfusion. Measurements included hemodynamics, blood flow studies, and two-dimensional echocardiography.

Table I. Hemodynamic data

\begin{tabular}{|c|c|c|c|c|c|c|}
\hline & \multicolumn{2}{|c|}{$H R$} & \multicolumn{2}{|c|}{$M A P$} & \multicolumn{2}{|c|}{$L A P$} \\
\hline & $\begin{array}{c}\text { Group I } \\
(n=7)\end{array}$ & $\begin{array}{c}\text { Group II } \\
(n=10)\end{array}$ & $\begin{array}{c}\text { Group I } \\
(n=7)\end{array}$ & $\begin{array}{c}\text { Group II } \\
(n=10)\end{array}$ & $\begin{array}{c}\text { Group } I \\
(n=7)\end{array}$ & $\begin{array}{l}\text { Group II } \\
(n=10)\end{array}$ \\
\hline Baseline & $151 \pm 4$ & $139 \pm 6$ & $133 \pm 8$ & $122 \pm 8$ & $2 \pm 0.3$ & $1 \pm 0.2$ \\
\hline $2 \mathrm{hr} \mathrm{occ}$ & $144 \pm 9$ & $147 \pm 7$ & $122 \pm 1$ & $112 \pm 8$ & $3 \pm 0.6$ & $2 \pm 0.3^{*}$ \\
\hline $1 \mathrm{hr}$ rep & & $163 \pm 9$ & & $107 \pm 9$ & & $3 \pm 0.5$ \\
\hline $2 \mathrm{hr}$ rep & & $131 \pm 14$ & & $111 \pm 9$ & & $2 \pm 0.4$ \\
\hline
\end{tabular}

HR, Heart rate; LAP, left atrial pressure; MAP, mean arterial pressure; occ, occlusion; rep, reperfusion.

${ }^{*} p<0.05$ versus baseline.

Table II. Edema data

\begin{tabular}{|c|c|c|c|c|c|}
\hline & & \multicolumn{2}{|c|}{ Ischemic zone } & \multicolumn{2}{|c|}{ Normal zone } \\
\hline & & Subendo & Subepi & Subendo & Subepi \\
\hline \multirow[t]{2}{*}{$\% \mathrm{H}_{2} \mathrm{O}$} & Group I $(n=7)$ & $78.8 \pm 0.3^{*}$ & $74.8 \pm 1.1$ & $77.1 \pm 0.2^{*}$ & $76.8 \pm 0.3$ \\
\hline & Group II $(n=10)$ & $84.5 \pm 0.6^{*}$ & $82.8 \pm 0.8$ & $79.1 \pm 0.7$ & $78.8 \pm 0.5$ \\
\hline \multirow[t]{2}{*}{$\mathrm{T} 1$ (msec) } & Group I $(n=7)$ & $707.8 \pm 12.5 \dagger$ & $641.7 \pm 20.5$ & $652.1 \pm 9.1 \dagger$ & $635.2 \pm 9.2$ \\
\hline & Group II $(n=10)$ & $813.2 \pm 36.2 \dagger$ & $760.5 \pm 34.7$ & $679.1 \pm 12.5$ & $672.8 \pm 16.6$ \\
\hline \multirow[t]{2}{*}{$\mathrm{T} 2$ (msec) } & Group I $(n=7)$ & $54.7 \pm 0.8$ & $54.0 \pm 1.4$ & $50.7 \pm 1.0$ & $48.8 \pm 1.4$ \\
\hline & Group II $(n=10)$ & $78.7 \pm 6.3$ & $73.1 \pm 4.0$ & $54.1 \pm 1.5$ & $54.4 \pm 1.7$ \\
\hline
\end{tabular}

Subendo, Subendocardium; Subepi, subepicardium.

${ }^{*} p<0.05$ versus subepicardium; $\dagger p<0.01$ versus subepicardium.

Statistical analysis. Values are shown as the mean \pm SEM. Comparisons were made using a two-tailed Student's $t$ test with a Bonferroni correction when comparisons were made over time with respect to baseline values. Statistical significance was determined at probabilities of $p<0.05$.

\section{RESULTS}

Hemodynamics (Table I). Hemodynamic measurements other than left atrial pressure showed no significant changes over time within either group or between the groups. However, there was a trend of de- creased mean arterial pressure and increased left atrial pressure during occlusion and during reperfusion in both groups. In addition, there was an increase in left atrial pressure in group II at 2 hours occlusion versus baseline that was not present in group I, but did not reach significance between the groups.

NMR spectroscopy (Table II, Fig. 3). Subendocardial $\mathrm{T} 1$ relaxation times were prolonged in the central ischemic zone ( $707.8 \pm 12.5 \mathrm{msec})$ with respect to the normal zone $(652.1 \pm 9.1 \mathrm{msec})$ in group I 


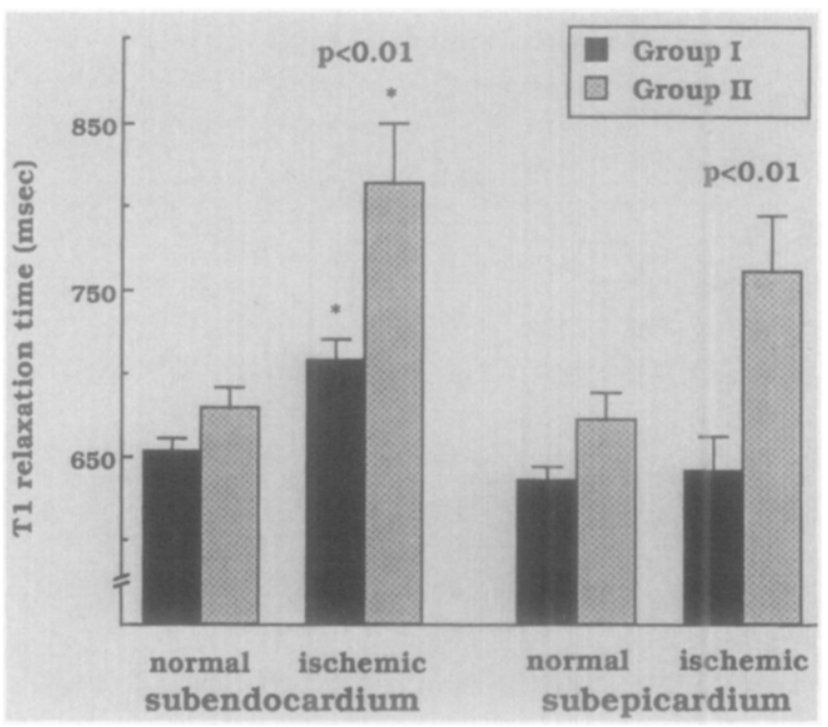

Fig. 3. T1 relaxation times in the normal and central ischemic zones of the subendocardium and subepicardium of group I (2-minute occlusion) and group II (2-minute occlusion/2-minute reperfusion). Note the prolonged relaxation times of the subendocardium versus the subepicardium in the ischemic zone of both groups (" $p<0.01$ versus subepicardium). Group II had greater relaxation times than group $I$ in the ischemic subendocardium and subepicardium $(p<0.01)$.

( $p<0.05$ ), although no significant difference was observed in the subepicardium. Group II demonstrated similar increases transmurally with subendocardial normal zone values increased from $679.1 \pm 12.5 \mathrm{msec}$ to $813.2 \pm 36.2 \mathrm{msec}$ in the central ischemic zone $(p<0.005)$ and subepicardial values increased from $672.8 \pm 16.6 \mathrm{msec}$ to $760.5 \pm 34.7 \mathrm{msec}(p<0.01)$. When the central ischemic zone of the reperfusion group (group II) was compared with that of the occlusion group (group I), group II was found to have significantly longer relaxation times than group $I$ in both the subendocardium $(p<0.01)$ and the subepicardium $(p<0.01)$. These increased central ischemic zone relaxation times showed a transmural gradient after occlusion with further prolongation in the subendocardium when compared with the subepicardium: $707.8 \pm 12.5 \mathrm{msec}$ in the subendocardium compared with $641.7 \pm 20.5 \mathrm{msec}$ in the subepicardium $(p<0.01)$. Similar T1 time differences were evident after reperfusion as the subendocardial relaxation time of $813.2 \pm 36.2 \mathrm{msec}$ was greater $(p<0.01)$ than the subepicardial time of $760.5 \pm 34.7$ msec. No significant differences were observed between the groups in the normal zone in either the subendocardium or subepicardium.

T2 relaxation times following occlusion had in-

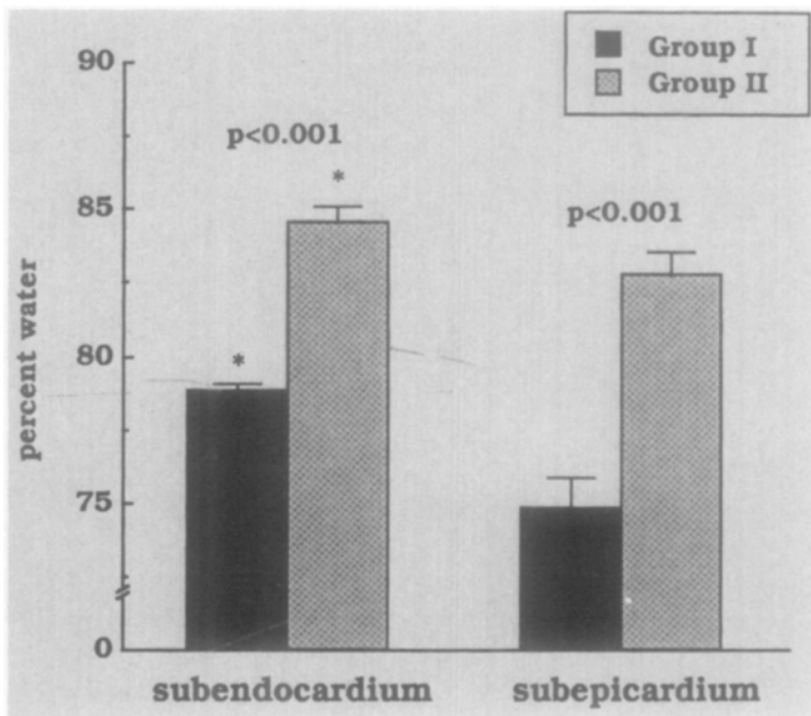

Fig. 4. Percent water content of the ischemic zone comparing the subendocardium and subepicardium in group I (2-minute occlusion) and in group II (2-minute occlusion/ 2 -minute reperfusion). Note the transmural gradient following occlusion ( $p<0.05$ versus subepicardium) and following reperfusion ( ${ }^{*} p<0.05$ versus subepicardium). Group II had higher water content transmurally $(p<$ 0.001 ).

creased values in the central ischemic zone with respect to the normal zone in the subendocardium $(54.7 \pm 0.8$ versus $50.7 \pm 1.0 \mathrm{msec}, p<0.05)$ and in the subepicardium $(54.0 \pm 1.4$ versus $48.8 \pm 1.4 \mathrm{msec}$ $(p<0.01)$. Similar increases were found following reperfusion in both the subendocardium $(78.7 \pm 6.3$ versus $54.1 \pm 1.5 \mathrm{msec}, p<0.01)$ and the subepicardium $(73.1 \pm 4.0$ versus $54.4 \pm 1.7 \mathrm{msec}, p<0.001)$. Intergroup comparison revealed increased relaxation times following reperfusion in the subendocardium $(p<0.005)$ and in the subepicardium $(p<0.01)$. The T2 relaxation times showed no transmural gradient in either group in the central ischemic zone.

Percent water content (Table II, Fig. 4). There was an increase in water content in group $I$ in the subendocardial central ischemic zone $(78.8 \pm 0.3 \%)$ versus the normal zone $(77.1 \pm 0.2 \%, p<0.005)$, although increases in subepicardial water content did not reach statistical significance. Group II also exhibited increases in tissue percent water transmurally as subendocardial water content increased from $79.1 \pm 0.7 \%$ to $84.5 \pm 0.6 \%(p<0.001)$ from the normal zone to the central ischemic zone and from $78.8 \pm 0.5 \%$ to $82.8 \pm 0.8 \% \quad(p<0.001)$ in the subepicardium. Further augmentation of water content was noted after reperfusion when compared with occlusion in both the subendocardium $(p<0.001)$ and the subepicardium $(p<0.001)$. In terms of the 


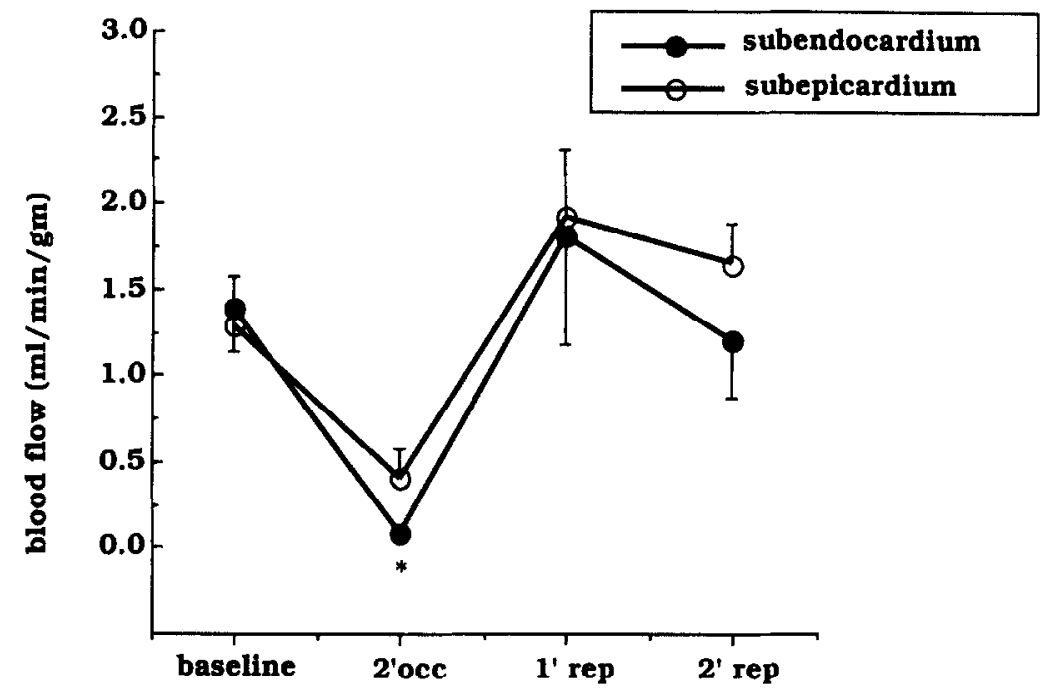

Fig. 5. Transmural blood flow of group II at baseline, at 2 hours of occlusion (occ), and at 1 and 2 hours of reperfusion ( $r e p)$. Note the lower flow in the subendocardium than subepicardium at occlusion $\left({ }^{*} p<0.05\right.$ versus subepicardium), which is not apparent at 1 hour of reperfusion, but returns at 2 hours of reperfusion.

Table III. Transmural blood flow

\begin{tabular}{|c|c|c|c|c|}
\hline & \multicolumn{2}{|c|}{ Ischemic zone } & \multicolumn{2}{|c|}{ Normal zone } \\
\hline & Group I & Group $I I$ & Group I & Group II \\
\hline \multicolumn{5}{|c|}{ Subendocardium } \\
\hline Baseline & $1.49 \pm 0.27$ & $1.39 \pm 0.22$ & $1.32 \pm 0.17$ & $1.55 \pm 0.29$ \\
\hline $2 \mathrm{hr} \mathrm{occ}$ & $0.03 \perp 0.01$ & $0.08 \pm 0.04$ & $1.17 \pm 0.24$ & $1.80 \pm 0.39$ \\
\hline 1 hr rep & & $1.81 \pm 0.60$ & & $2.14 \pm 0.53$ \\
\hline $2 \mathrm{hr}$ rep & & $1.20 \pm 0.31$ & & $1.94 \pm 0.39$ \\
\hline \multicolumn{5}{|c|}{ Midmyocardium } \\
\hline Baseline & $1.54 \pm 0.28$ & $1.33 \pm 0.23$ & $1.32 \pm 0.20$ & $1.48 \pm 0.29$ \\
\hline $2 \mathrm{hr} \mathrm{occ}$ & $0.14 \pm 0.04$ & $0.24 \pm 0.08$ & $1.16 \pm 0.22$ & $1.72 \pm 0.39$ \\
\hline $1 \mathrm{hr}$ rep & & $1.35 \pm 0.24$ & & $1.95 \pm 0.48$ \\
\hline $2 \mathrm{hr}$ rep & & $1.06 \pm 0.19$ & & $1.84 \pm 0.36$ \\
\hline \multicolumn{5}{|c|}{ Subepicardium } \\
\hline Baseline & $1.33 \pm 0.21$ & $1.28 \pm 0.26$ & $1.24 \pm 0.17$ & $1.38 \pm 0.23$ \\
\hline $2 \mathrm{hr} \mathrm{occ}$ & $0.40 \pm 0.13$ & $0.40 \pm 0.14$ & $1.17 \pm 0.19$ & $1.66 \pm 0.32$ \\
\hline $1 \mathrm{hr}$ rep & & $1.92 \pm 0.35$ & & $1.89 \pm 0.43$ \\
\hline $2 \mathrm{hr}$ rep & & $1.63 \pm 0.22$ & & $1.84 \pm 0.40$ \\
\hline
\end{tabular}

All values are in milliliters per minute per gram.

Abbreviations as in Table I.

transmural water content in the central ischemic zone, the water content was significantly higher in the subendocardium than in the subepicardium following occlusion $(p<0.01)$ and following reperfusion $(p<0.01)$.

Correlations between percent water content and NMR relaxation times in the central ischemic zone were determined. Both subendocardial and subepicardial T1 values correlated well with percent water content $(r=0.70, p<0.01 ; r=0.86, p<0.001$, respectively). T2 relaxation times showed similar correlations in the subendocardium $(r=0.80, p<0.001)$ and in the subepicardium $(r=0.72, p<0.01)$.
Transmural blood flow (Table III, Fig. 5). No statistical differences were found between the protocol groups. Both groups had a severe reduction of myocardial blood flow during occlusion in the central ischemic zone. This reduction was present transmurally, but there was a gradient with lower flow at occlusion in the subendocardium of both groups when compared with the midmyocardium $(p<0.005)$ and when compared with the subepicardium $(p<0.05)$.

In group II, at 1 hour reperfusion flow returned to near baseline levels in the subendocardium and midmyocardium. Blood flow was augmented above baseline levels in the subepicardium $(p<0.005$ versus 


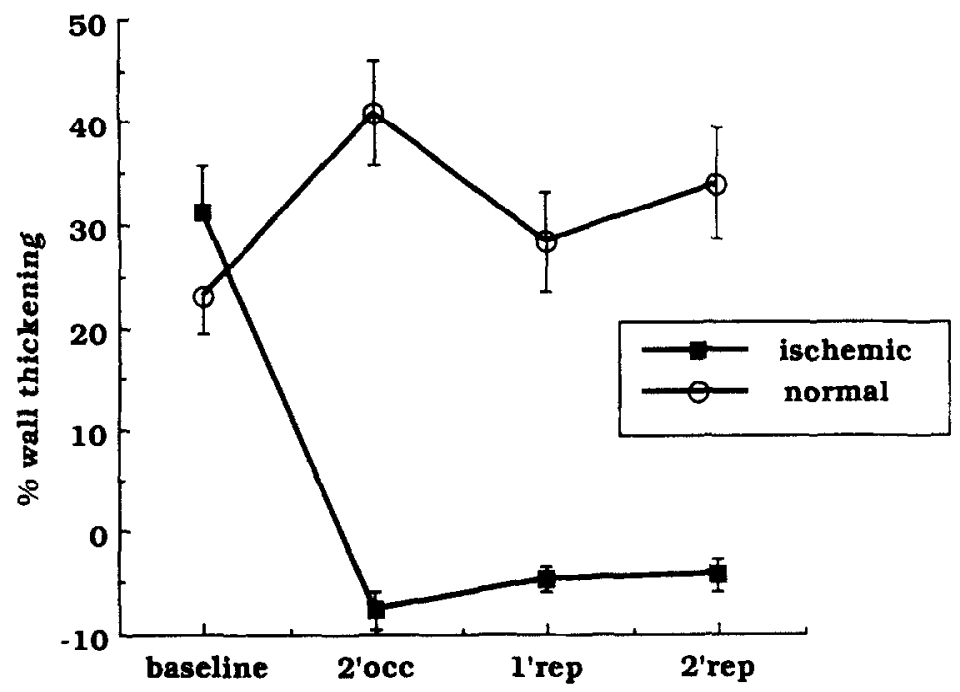

Fig. 6. Percent wall thickening of group II in the central ischemic zone (ischemic) to the central normal zone (normal). Note the thinning of the ischemic zone during occlusion with little improvement during reperfusion.

baseline), but this was not remarkably different from that in the normal zone. By 2 hours reperfusion, flow was attenuated in the central ischemic midmyocardium compared with that in the normal zone $(p<0.005)$, and a similar trend was also observed in the subendocardium. Although the central ischemic subepicardial blood flow was above baseline levels, the central ischemic zone flow was still much lower than normal zone flow $(p<0.05)$. Correlations were also not observed between blood flow at occlusion or during reperfusion, and percent water content or $\mathrm{T} 1$ and $\mathrm{T} 2$ relaxation times.

Functional data (Fig. 6). There were no significant intergroup functional differences at baseline or at occlusion. However, in the central ischemic zone, there was marked thinning of the left ventricular wall at occlusion in both groups $(p<0.005)$ that persisted with little improvement during reperfusion $(p<0,005)$. The normal zone demonstrated augmented thickening at occlusion in the reperfusion group that was not present in the occlusion group, although these differences were not statistically significant between groups.

End-systolic area increased during occlusion and remained increased during reperfusion. End-diastolic area also increased following occlusion in the reperfusion group $(p<0.001)$ but not in the occlusion group, although no differences were seen between the two groups. This increased area returned to baseline values during reperfusion. Although area ejection fraction was reduced during occlusion in both groups, area ejection fraction improved somewhat following reperfusion in group II, but remained depressed. The regional indices of dysfunction, as defined by the degree and extent of dysfunction, demonstrated no improvement with reperfusion. Correlations were not observed between percent wall thickening and NMR relaxation times or percent water content.

\section{DISCUSSION}

Our data indicate that following coronary occlusion, a transmural increase in myocardial water content occurs in the central ischemic zone, as determined by NMR-derived $\mathrm{T} 1$ and $\mathrm{T} 2$ relaxation times and percent water content. This myocardial edema is greater in the subendocardium than in the subepicardium, and is further augmented by reperfusion. As a result, a transmural gradient of edema is also present from the subendocardium to subepicardium following coronary reperfusion.

It is well known that impaired cell volume regulation, interstitial fluid accumulation, and focal structural defects in the cell membrane integrity are early manifestations of ischemic injury. ${ }^{15-17}$ Willerson et al. ${ }^{17}$ demonstrated that myocardial edema can occur as early as $\mathbf{4 0}$ minutes after coronary occlusion, and is associated with a significant decrease in $\mathrm{Na} / \mathrm{K}$ adenosine triphosphatese (ATPase) activity in the ischemic region, which probably contributes to the cell swelling. During a period of ischemia, the $\mathrm{Na} / \mathrm{K}$ ATPase pump is unable to actively extrude $\mathrm{Na}$ from the interior of cells, and this results in intracellular movement of $\mathrm{Na}, \mathrm{Cl}$, and $\mathrm{H}_{2} \mathrm{O}$ with subsequent cell swelling. Even relatively brief periods of ischemia (15 minutes) and reperfusion may lead to myocardial edema as a result of increased permeability because of endothelial injury. ${ }^{18}$ Ischemia produces functional 
coronary microvascular injury that may further contribute to this tissue edema. Thus as the duration and severity of ischemia increase, microvascular permeability increases. ${ }^{18}$ Following more prolonged ischemia and necrosis, there is a disruption of the myocardial cell membrane and a loss of intracellular edema. This edema correlates with the extent of eventual myocardial cell necrosis, ${ }^{19,20}$ but remaining viable cells may also demonstrate persistent cell swelling. ${ }^{16}$

Our results concur with those of previous studies that have observed an increase in myocardial relaxation times in the ischemic zone after coronary occlusion and reperfusion." For example, Johnston et al. ${ }^{4}$ found that increased NMR relaxation times were greater in the subendocardium than in the subepicardium following a 3-hour occlusion. Furthermore, other studies have shown that edema measured by NMR relaxation times is augmented by reperfusion compared with coronary occlusion. ${ }^{4,9,10}$ In agreement with our results, both Ratner et al. ${ }^{6}$ and Johnston et al. ${ }^{4}$ observed an increase in T1 and T2 relaxation times following occlusion in the subendocardium versus the subepicardium, and following reperfusion, this transmural gradient was augmented. Thus both in the setting of ischemia and of reperfusion, a transmural gradient of myocardial edema from the subendocardium to the subepicardium occurs.

The transmural gradient of myocardial edema may be related to other transmural pathophysiologic events that are known to occur during ischemia and reperfusion. Following coronary occlusion, we observed a transmural blood flow gradient in the central ischemic zone, with blood flow reduced to nearly zero in the subendocardium, with relatively greater flow in the subepicardium. This is in concurrence with the findings of previous studies that have shown that the subepicardium receives preferential collateral flow. ${ }^{21-24}$ Fukunami et al. ${ }^{25}$ found a slight transmural gradient at the onset of ischemia that increased at 30 minutes of ischemia with greater collateral flow in the subepicardium. By 24 hours of occlusion, there was an increase in midmyocardial and subepicardial blood flow with again no improvement in subendocardial blood flow. Thus the transmural gradient of myocardial edema may then be attributed to greater ischemic injury from lower blood flow in the subendocardium. The greater oxygen demand in the subendocardium, due to greater wall stress and other factors including greater extravascular systolic tissue pressure ${ }^{26,27}$ and lower oxygen

*References 1-4, 6, 8-10, and 12 . tension $^{27,28}$ may exacerbate this ischemic blood flow gradient.

The vulnerability of the subendocardium to ischemic injury is well known and occurs in a wavelike pattern of necrosis beginning in the subendocardium and progressing outward to the subepicardium with prolonged coronary occlusion. ${ }^{29}$ This gradient is likewise seen following coronary reperfusion, with maximum stunning and slowest recovery found in the subendocardium..$^{30}$ In addition, Sheppard and Gavin $^{31}$ have reported a transmural progression of no-reflow across the myocardial wall. In this regard, we found that the transmural flow gradient diminished at 1 hour of reperfusion as flows in all myocardial layers approached values in the normal zone. However, by 2 hours of reperfusion, a transmural flow gradient was again evident, with lower flow again present in the subendocardium. This suggests an early development of the no-reflow phenomenon in the subendocardium prior to that in the subepicardium, which may be indicative of greater ischemic and reperfusion injury. A similar transmural gradient in the rate at which the ischemic myocardium utilizes $\mathrm{ATP}^{32}$ and develops irreversible cell injury may further contribute to the development of the transmural gradient of myocardial edema. ${ }^{33}$ The differences in ATP utilization may also be caused by the gradient in the distribution of blood flow, since a linear relationship between ATP depletion and blood flow exists at occlusion. ${ }^{25}$

In view of these considerations, it was of interest that correlations were not observed in our study between NMR relaxation times and myocardial blood flow at occlusion or reperfusion. Previous studies $^{4,6,12}$ have shown inverse correlations between occlusion blood flow and T1/T2 times following coronary occlusion. The apparent discrepancy between the results of these studies and those of our study may be attributed to the narrow range of blood flows that we used to define severe ischemia. Animals with subendocardial blood flows greater than $0.2 \mathrm{ml} /$ $\mathrm{min} / \mathrm{gm}$ were considered to have significant collaterals and were excluded from analysis, whereas other investigators have accepted a much wider range of ischemic blood flows. As a result of our uniformly low blood flows, the ability to observe significant correlations was minimized.

Our study also found no correlation between relaxation times and reperfusion blood flow. Previous studies have found varied results; NMR relaxation times have been found to have been directly correlated $^{6}$ with reperfusion blood flow, whereas other investigators ${ }^{12}$ found no such correlation. As reperfusion augments fluid and electrolyte imbal- 
ance, early reperfusion blood flows should correlate directly with $\mathrm{T} 1$ and $\mathrm{T} 2$. If edema were involved in no-reflow, one might expect to see an inverse correlation with NMR and late reperfusion blood flow, as an increase in edema would further enhance noreflow. The fact that such a correlation was not observed argues against the hypothesis that myocardial edema contributes to no-reflow. In further support of this, no improvement in reperfusion blood flow and no-reflow was found following edema reduction by hyperosmotic mannitol infusion. ${ }^{12,34}$

Myocardial edema may impair both tissue nutrient delivery and washout of metabolic by-products, which in turn can result in myocardial dysfunction. ${ }^{35,36}$ However, we found no correlations between NMR relaxation times and wall thickening. Furthermore, a recent study ${ }^{34}$ has suggested that edema does not play a role in early myocardial stunning, as no improvement in wall thickening was observed following reduction of edema by hyperosmotic mannitol infusion. Moreover, Cross et al. ${ }^{37}$ found that edema formation did not influence contractile stength. They did, however, observe a decrease in diastolic distensibility in proportion to fluid accumulation. Thus although edema may not influence systolic contractile performance, it may contribute to increased diastolic stiffness by reducing compliance and altering filling properties. ${ }^{35}$

Our results have clinical significance related to the interpretation of NMR imaging. NMR characterizes proton density, found primarily in water in a variety of chemical forms, in the intact animal. In the setting of acute myocardial ischemic injury, the resulting NMR abnormalities represent regional myocardial edema. Thus insights into edema formation and localization should lead to greater understanding of NMR images. Since there is a gradient in the amount of injury, images may be able to localize infarction as subendocardial or transmural. Furthermore, the extent and distribution of edema reflected by NMR parameters may provide a useful noninvasive indicator as to the success of coronary reperfusion following intravenous thrombolytic therapy.

In conclusion, a transmural increase in myocardial percent water content was observed in the central ischemic zone following occlusion and following reperfusion. These increases were also found by NMR relaxometry, as determined by increased $\mathrm{T} 1$ and $\mathrm{T} 2$ relaxation times. This ischemia-induced edema was augmented by reperfusion transmurally. The subendocardium demonstrated greater edema than the subepicardium, both after occlusion and after reperfusion, by both percent water content and $\mathrm{T} 1$ values. This transmural gradient may be related to greater ischemic damage in the subendocardium compared with the relatively protected subepicardium. These observations should provide greater insight into the interpretation and analysis of NMR images in the setting of coronary occlusion and reperfusion.

We greatly appreciate the advice of Thomas L. Chenevert, $\mathrm{PhD}$, and the technical assistance of Marsha Gallagher and Staci Haarer.

\section{REFERENCES}

1. Higgins CB, Herfkens R, Lipton MJ, Sievers R, Sheldon P, Kaufman L, Crooks LE. Nuclear magnetic resonance imaging of acute myocardial infarction in dogs: alterations in magnetic relaxation times. Am J Cardiol 1983:52:184-8.

2. Wesby G, Higgins CB, Lanzer P, Botvinick E, Lipton MJ. Imaging and characterization of acute myocardial infarct in vivo by gated nuclear magnetic resonance. Circulation 1984;69:12530 .

3. Buda AJ, Aisen AM, Juni JE, Gallagher KP, Zotz RJ. Detection and sizing of myocardial ischemia and infarction by nuclear magnetic resonance imaging in the canine heart. AM HeART J 1985;110:1284-90.

4. Johnston DL, Brady TJ, Ratner AV, Rosen BR, Newell JB, Pohost GM, Okada RD. Assessment of myocardial ischemia with proton magnetic resonance: effects of a three hour occlusion with and without reperfusion. Circulation 1985;71:595601.

5. Pflugfelder PW, Wisenberg G, Prato FS, Carroll SE, Turner KL. Early detection of canine myocardial infarction by magnetic resonance imaging in vivo. Circulation 1985;71:587-94.

6. Ratner AV, Okada RD, Newell JB, Pohost GM. The relationship between proton nuclear magnetic resonance relaxation parameters and myocardial perfusion with acute coronary arterial occlusion and reperfusion. Circulation 1985;71:823-8.

7. Pflugfelder PW, Wisenberg G, Prato FS, Turner KL. Serial imaging of canine myocardial infarction by in vivo nuclear magnetic resonance. J Am Coll Cardiol 1986;7:843-9.

8. Tscholakoff D, Higgins CB, Sechtem U, Caputo G, Derugin N. MRI of reperfused myocardial infarct in dogs. AJR 1986; 146:925-30.

9. Johnston DL, Lui P, Rosen BR, Levine RA, Beaulieu PA, Brady TJ, Okada RD. In vivo detection of reperfused myocardium by nuclear magnetic resonance imaging. J Am Coll Cardiol 1987;9:127-35.

10. Wisenberg G, Prato FS, Carroll SE, 'Turner KL, Marshall T. Serial nuclear magnetic resonance imaging of acute myocardial infarction with and without reperfusion. AM HEART $J$ $1988 ; 115: 510-8$.

11. Bouchard A, Reeves RC, Cranney G, Bishop SP, Pohost GM. Assessment of myocardial infarct size by means of T2weighted $\mathrm{H}$ nuclear magnetic resonance imaging. AM HEAR' J 1989;117:281-9.

12. Miller DD, Johnston DL, Dragotakes D, Newell JB, Aretz T, Kantor HL, Brady TJ, Okada RD. Effect of hyperosmotic mannitol on magnetic resonance relaxation parameters in reperfused canine myocardial infarction. Magn Reson Imaging 1989;7:79-88.

13. Ryan T, Tarver RD, Duerk JL, Sawada SG, Hollenkamp NC. Distinguishing viable from infarcted myocardium after experimental ischemia and reperfusion by using nuclear magnetic resonance imaging. I Am Coll Cardiol 1990;15:1355-64

14. Buda AJ, Zotz RJ, Gallagher KP: Characterization of the functional border zone around regionally ischemic myocardium using circumferential flow-function maps. I Am Coll Cardiol 1986;8:150-8.

15. Jennings RB, Sommers HM, Kaltenbach JP, West JJ. Electrolyte alterations in acute myocardial ischemic injury. Circ Res 1974;14:260-9. 
16. Powell WJ, DiBona DR, Flores J, Leaf A. The protective effect of hyperosmotic mannitol in myocardial ischemia and necrosis. Circulation 1976;54:603-15.

17. Willerson JT, Scales F, Mukherjee A, Platt M, Templeton G, Fink B, Buja M. Abnormal myocardial fluid retention as an early manifestation of ischemic injury. Am $J$ Pathol 1977;87:159-88.

18. Dauber IM, VanBenthuysen, McMurtry IF, Wheeler GS, Lesnerfsky EJ, Horwitz LD, Weil JV. Functional coronary microvascular injury evident as increased permeability due to brief ischemia and reperfusion. Circ Res 1990;66:986-98.

19. Carlson RE, Aisen AM, Gallagher MA, Chenevert TL, Buda AJ. Proton nuclear magnetic resonance relaxation spectroscopy reliably predicts the severity of ischemic injury $[\mathrm{Ab}-$ stract]. Circulation 1988;78(suppl II):341.

20. DiBona DR, Powell WJ. Quantitative correlation between cell swelling and necrosis in myocardial ischemia in dogs. Circ Res 1980;47:653-65.

21. Bache RJ, Corr FR, Greenfield JC Jr. Myocardial blood flow distribution during ischemia-induced coronary vasodilation in the unanesthetized dog. J Clin Invest 1974;54:1462-72.

22. Jugdutt BI, Hutchins GM, Bulkley BH, Becker LC. Myocardial infarction in the conscious dog: three-dimensional mapping of infarct, collateral flow and region at risk. Circulation 1979;60:1141-50.

23. Nienaber CH, Gottwik M, Winkler B, Schaper W. The relationship between the perfusion deficit, infarct size and time after experimental coronary artery occlusion. Basic Res Cardiol 1983;78:210-26.

24. Downey JM. Why the endocardium? In: Hearse DJ, Yellon DM, eds. Therapeutic approaches to myocardial infarct size limitation. New York: Raven Press, 1984:125-38.

25. Fukunami M, Yellon DM, Kudoh Y, Maxwell MP, Wyse RKH, Hearse DJ. Spatial and temporal characteristics of the transmural distribution of collateral flow and energy metabolism during regional myocardial ischemia in the dog. Can J Cardiol 1987;3:94-103.
26. Kirk ES, Honig AC. An experimental and theoretical analysis of myocardial tissue pressure. Am J Physiol 1964;207:361-7.

27. Kirk ES, Honig CR. Nonuniform distribution of blood flow and gradients of oxygen tension within the heart. Am J Physiol 1964;297:661-8.

28. Weiss HR, Sinha AK. Regional oxygen saturation of small arteries and veins in the canine myocardium. Cir Res 1978;42:11925.

29. Reimer KA, Jennings RB. The "wavefront phenomenon" of myocardial ischemic cell death. Lab Invest 1979;40:633-44.

30. Bolli R, Patel BS, Hartley CJ, Thornby JI, Jeraudi MO, Roberts $R$. Nonuniform transmural recovery of contractile function in stunned myocardium. Am J Physiol 1989;257:H375-85.

31. Sheppard AJ, Gavin JB. The transmural progression of the no-reflow phenomenon in globally ischemic hearts. Basic Res Cardiol 1988;83:611-7.

32. DeBoer LWV, Ingwall JS, Kloner RA, Braunwald E. Prolonged derangements of canine myocardial purine metabolism after a brief coronary artery occlusion not associated with anatomic evidence of necrosis. Proc Natl Acad Sci USA 1980;77: 5471-5.

33. Humphrey SM, Vanderwee MA, Gavin JB. Transmural differences in the postischemic recovery of cardiac energy metabolism. Am J Pathol 1988;131:5-11.

34. Carlson RE, Aisen AM, Gallagher M, Buda AJ. Does the reduction in myocardial edema improve blood flow or functional recovery? [Abstract] Clin Res 1989;37:249A.

35. Pogatsa G, Dubecz E, Gabor G. The role of myocardial edema in the left ventricular diastolic stiffness. Basic Res Cardiol 1976;71:263-9.

36. Laine GA. Change in $\mathrm{dP} / \mathrm{dtmax}$ as an index of myocardial microvascular permeability. Circ Res 1987;61:203-8.

37. Cross CE, Rieben PA, Salisbury PF. Influence of coronary perfusion and myocardial edema on pressure-volume diagram of left ventricle. Am J Physiol 1961:201:102-8. 